\title{
Resveratrol affords protection against peroxynitrite-mediated endothelial cell death: A role for intracellular glutathione
}

\author{
Paula M. Brito, Anabela Mariano, Leonor M. Almeida, Teresa C.P. Dinis* \\ Laboratório de Bioquímica, Faculdade de Farmácia, Universidade de Coimbra and Centro de Neurociências, \\ Universidade de Coimbra, 3000-295 Coimbra, Portugal \\ Received 14 July 2006; received in revised form 14 September 2006; accepted 19 September 2006 \\ Available online 28 September 2006
}

\begin{abstract}
Atherosclerosis, the main cause of cardiovascular disease (CD), is a chronic inflammatory condition associated with an overproduction of oxidant species, namely peroxynitrite, which is a powerful oxidant that reacts directly with all biomolecules. Glutathione is an efficient scavenger of peroxynitrite, so, modulation of glutathione synthesis may provide a strategy to selectively protect cells from this oxidant. Here, we investigated the ability of resveratrol, a component of red wine, to prevent peroxynitrite-mediated endothelial cells toxicity and the underlying mechanism. Bovine aortic endothelial cells (BAEC) in primary cultures were treated with authentic peroxynitrite and the cell viability and intracellular glutathione contents were assessed. Our results demonstrate that a long pre-incubation $(14 \mathrm{~h})$ of BAEC with resveratrol $(1-50 \mu \mathrm{M})$ leads to the endothelial cells rescue from injury triggered by authentic peroxynitrite by a mechanism of up-regulation of the intracellular GSH content, for the highest resveratrol concentration tested. Considering the importance of GSH in regulation of cell life, this capacity of resveratrol provides a new mechanism for its cardioprotective effects and may contribute to the development of novel therapeutic strategies.
\end{abstract}

(C) 2006 Elsevier Ireland Ltd. All rights reserved.

Keywords: Resveratrol; Intracellular glutathione; Peroxynitrite; Cell death; Atherosclerosis

\section{Introduction}

Atherosclerosis is a chronic inflammatory condition characterized by lipid accumulation, smooth muscle proliferation and monocyte recruitment to the endothelium following endothelial cell dysfunction associated with

Abbreviations: BSO, L-buthionine $S R$-sulfoximine; $\mathrm{ONOO}^{-}$, peroxynitrite; BAEC, bovine aortic endothelial cells; LDL, low density lipoproteins; GSH, glutathione; GSSG, glutathione disulfide; Res, resveratrol

* Corresponding author at: Laboratório de Bioquímica, Faculdade de Farmácia Couraça dos Apóstolos 51, r/c 3000-295 Coimbra, Portugal. Tel.: +351 239852562; fax: +351239852569.

E-mail address: tcpdinis@ci.uc.pt (T.C.P. Dinis). oxidative stress [1]. This oxidative stress is the result of an increase of reactive species that are able to mediate LDL oxidation and several deleterious cellular effects that may culminate in cell death. Virtually, all vascular cells produce reactive species, via specific cellular enzymes, as NADPH and xanthine oxidases, the main sources of superoxide anion $\left(\mathrm{O}_{2}{ }^{\bullet-}\right)$ production, and NO synthase which produces nitric oxide $\left(\mathrm{NO}^{\bullet}\right)$ [2]. Although $\mathrm{NO}^{\bullet}$ is an antiatherogenic molecule due to its beneficial effects on vascular wall [2], it can react rapidly with $\mathrm{O}_{2}{ }^{\bullet-}$, in a diffusion-controlled reaction, leading to the formation of peroxynitrite $\left(\mathrm{ONOO}^{-}\right)$, a powerful oxidant and nitrating species [3]. Peroxynitrite may oxidize and covalently modify a wide range of biomolecules, including DNA, proteins and lipids, 
as well as various low-molecular-weight biomolecules [4-6]. These modifications can affect important cellular functions in such a way that cell homeostasis may be compromised and subsequently apoptosis or necrosis may occur. The involvement of peroxynitrite in atherosclerosis has been suggested either by its ability to oxidize LDL, or by the extensive nitration of protein tyrosine observed in human atherosclerotic lesions [7-10]. Then, it is crucial to counteract peroxynitrite damaging effects and one of the possible strategies is to scavenge it.

Glutathione (GSH) is the principal non-protein thiol involved in the antioxidant defence and is the major contributor to the cellular redox state [11]. GSH is ubiquitously present in all cell types at millimolar concentrations and is distributed among nucleus, endoplasmic reticulum and mitochondria. Despite the fact that the rate constant for the reaction between GSH and peroxynitrite is not too high, the high intracellular GSH concentration turns it into the most likely and important endogenous low-molecular-weight molecule for scavenging peroxynitrite [12]. Additionally, GSH is implicated in peroxynitrite-detoxification through its enzymatic system, being glutathione peroxidase able to reduce peroxynitrite to nitrite at the expenses of GSH. Actually, Ma et al. [13] have shown that GSH depletion in hypercholesterolemic rabbits exacerbated the damaging effects of peroxynitrite on vasculature functions, strengthening the crucial role of GSH in peroxynitrite detoxication.

On the other hand, resveratrol (3,4',5-trihydroxystilbene), a natural phytoalexin found in wine, specially red wine, has been suggested to be one of the active ingredients responsible for cardiovascular benefits of moderate wine consumption, due to its numerous biological activities such as inhibition of LDL oxidation, inhibition of smooth muscle cells proliferation and inhibition of platelet aggregation [14-17]. However, the underlying mechanisms responsible for its cardioprotective effects are still largely unknown. Recently, Cao and Li group has demonstrated that resveratrol induces an increase in GSH intracellular content in cardiomyocytes and smooth muscle cells $[18,19]$. Thus, following our previous work showing that resveratrol protects efficiently LDL against peroxynitrite-induced oxidation [15], and knowing that resveratrol increases GSH and that this molecule is relevant to peroxynitrite-detoxification, we hypothesized that resveratrol could prevent cell death by peroxynitrite by increasing GSH. Accordingly, in this study, using primary cultures of bovine aortic endothelial cells (BAEC) as a model system, we determined the resveratrol concentration-dependent induction of intracellular
GSH and the protection afforded by resveratrol against peroxynitrite-elicited endothelial cell death.

Our data indicate that resveratrol is able to decrease the programmed cell death in BAEC stimulated by bolus addition of authentic peroxynitrite, not by a direct reaction with this oxidant but rather by increasing GSH intracellular content.

\section{Materials and methods}

\subsection{Materials}

General laboratory chemicals and some specific ones, namely, collagenase, gelatine, streptomycin/penicillin, MTT, BSO, Hoechst 33258, ortho-phthaldeyde and GSH were obtained from Sigma Chemicals (St. Louis, MO). For cell culture, Dulbecco's modified Eagle's medium (DMEM), trypsin $0.25 \%$, fungizone, fetal bovine serum (FBS) and phosphate-buffered saline (PBS) pH 7.4, were purchased from Gibco-Invitrogen. Resveratrol was from Extrasynthèse (Genay, France).

\subsection{Primary cultures of bovine aortic endothelial cells}

Bovine aortic endothelial cells (BAEC) were obtained from thoracic aorta by treatment with collagenase $(2 \mathrm{mg} / \mathrm{ml})$. Cells were cultivated on gelatine-coated tissue culture plastic in DMEM supplemented with $10 \%$ fetal bovine serum, $100 \mathrm{U} / \mathrm{ml}$ penicillin, $100 \mu \mathrm{g} / \mathrm{ml}$ streptomycin and $50 \mu \mathrm{g} / \mathrm{ml}$ fungizone at $37^{\circ} \mathrm{C}$, in a humidified atmosphere of $5 \% \mathrm{CO}_{2}$. Endothelial cells were identified by their cobblestone morphology and uptake of fluorescently labelled acetylated LDL. Cells were subcultured at confluences and used between the fourth and the seventh passage. Prior to the experiments, cells at $80 \%$ of confluence were starved in serum-free medium for $24 \mathrm{~h}$.

\subsection{Peroxynitrite synthesis}

Peroxynitrite was synthesized by using a quenched flow reactor, as previously described [20]. Briefly, an aqueous solution of $0.6 \mathrm{M} \mathrm{NaNO}_{2}$ was mixed rapidly with an equal volume of $0.7 \mathrm{M} \mathrm{H}_{2} \mathrm{O}_{2}$ containing $0.6 \mathrm{M}$ $\mathrm{HCl}$ and immediately quenched with the same volume of $1.5 \mathrm{M} \mathrm{NaOH}$. The solution was then frozen at $-20^{\circ} \mathrm{C}$ for approximately $24 \mathrm{~h}$. At this temperature, peroxynitrite concentrates into a dark yellow top layer (freeze fractionation), which was removed and passed through a short column of $\mathrm{MnO}_{2}$ for residual $\mathrm{H}_{2} \mathrm{O}_{2}$ remotion according to Uppu et al. [21]. Then it was stored at $-80^{\circ} \mathrm{C}$ 
under $\mathrm{N}_{2}$ atmosphere. Before use, $\mathrm{ONOO}^{-}$was always quantified from the absorbance at $302 \mathrm{~nm}$ in $1 \mathrm{~N} \mathrm{NaOH}$ $\left(\varepsilon=1670 \mathrm{M}^{-1} \mathrm{~cm}^{-1}\right)$.

\subsection{Peroxynitrite-induced oxidative stress}

In the experiments with $\mathrm{ONOO}^{-}$, cells were washed previously once and equilibrated with PBS (phosphate buffered saline with calcium and magnesium) $\mathrm{pH} 7.4$ for $5 \mathrm{~min}$. Subsequently, $\mathrm{ONOO}^{-}$, diluted in $10 \mathrm{mM} \mathrm{NaOH}$ to the required concentration, was delivered as a single bolus, at the respective concentrations, against one side of the dish while rapidly swirling the medium to assure optimal exposure of the cells to $\mathrm{ONOO}^{-}$before decomposition. Cells were exposed to $\mathrm{ONOO}^{-}$for $10 \mathrm{~min}$, after which they were washed and replaced in culture medium for $6 \mathrm{~h}$. No $\mathrm{pH}$ shift was observed during treatment with $\mathrm{ONOO}^{-}$. PBS rather than DMEM was used for peroxynitrite-treatment to avoid interfering reactions of $\mathrm{ONOO}^{-}$with the media constituents. The same volumes of either $10 \mathrm{mM} \mathrm{NaOH}$ (vehicle control) or decomposed $\mathrm{ONOO}^{-}\left(\mathrm{ONOO}^{-}\right.$was decomposed in PBS or $10 \mathrm{mM} \mathrm{NaOH}$ overnight) were used as controls. When required, cells were pre-incubated with resveratrol, BSO (buthionine sulfoximine) or both for $14 \mathrm{~h}$. At the end of the indicated time, the incubation medium was gently removed and the cells were incubated with peroxynitrite as described above. In these conditions, resveratrol or BSO were not present in the incubation medium throughout the experiment with peroxynitrite.

\subsection{Cell viability assay}

Cells $\left(0.5 \times 10^{6}\right.$ cells/well $)$ seeded in 6-well plates were incubated with various concentrations of BSO for $14 \mathrm{~h}$. Cell viability was then assessed by the MTT test according to Denizot and Lang [22]. Briefly, after the incubation period, the medium was removed, the cells were washed with PBS and further, $1 \mathrm{ml}$ of PBS containing $100 \mu \mathrm{l}$ of MTT $(1 \mathrm{~g} / \mathrm{l})$ was added to each well for $1 \mathrm{~h}$ at $37^{\circ} \mathrm{C}$. Formazan crystals were dissolved in DMSO and the absorbance was read at $530 \mathrm{~nm}$. Results were expressed as a percentage of control cells.

\subsection{LDH measurement}

The cell lysis (necrosis) was evaluated by the lactate dehydrogenase $(\mathrm{LDH})$ release. Lactate dehydrogenase released into the cultured medium was spectrophotometrically evaluated in an auto analyzer Synchron CX (Beckman Coulter) following the manufacturer's instructions. Results were expressed as percentage of total LDH release, obtained by division of the LDH activity in the supernatant by the LDH activity in supernatant plus the LDH activity in cell lysate.

\subsection{Nuclear morphology}

Cells were fixed with freshly prepared $4 \%(\mathrm{w} / \mathrm{v})$ paraformaldehyde in phosphate buffered saline (PBS, $\mathrm{pH}$ 7.4) for $15 \mathrm{~min}$ at room temperature and subsequently stained with Hoechst dye $33258(5 \mu \mathrm{g} / \mathrm{ml})$ for $15 \mathrm{~min}$, washed with PBS and mounted by using PBS/glycerol $(3: 1, v / v)$. Then, cells were examined by fluorescence microscopy, with a Nikon fluorescence microscope. Stained nuclei were scored according to the condensation and staining characteristics of chromatin. Apoptotic nuclei were identified by condensed chromatin and nuclear fragmentation and were counted in at least five random microscopic fields $(400 \times)$ per sample. Only cells that remained attached to the plates were observed. Mean values were expressed as the percentage of apoptotic nuclei.

\subsection{Measurement of cellular reduced and oxidized glutathione}

Intracellular levels of GSH and GSSG were determined by a fluorimetric assay as previously described [23]. In brief, cells were scrapped with $0.6 \mathrm{M}$ perchloric acid and recovered into $100 \mathrm{mM}$ sodium phosphate buffer containing $5 \mathrm{mM}$ EDTA, pH 8.0 at $4{ }^{\circ} \mathrm{C}$. Samples were centrifuged at $14,000 \mathrm{rpm}$ at $4{ }^{\circ} \mathrm{C}$ for $10 \mathrm{~min}$. A volume of $100 \mu \mathrm{l}$ of supernatant was incubated with $100 \mu \mathrm{l}$ of ortho-phthaldehyde $(0.1 \% \mathrm{w} / \mathrm{v}$ in methanol) and $1.8 \mathrm{ml}$ of $100 \mathrm{mM} \mathrm{Na} \mathrm{HPO}_{4}$ for $15 \mathrm{~min}$ at room temperature. For the GSSG determination the supernatant was previously treated during $30 \mathrm{~min}$ with $N$-ethylmaleimide (NEM) and then incubated with ortho-phthaldehyde in $100 \mathrm{mM} \mathrm{NaOH}$. Fluorescence intensity was then read in a Perkin-Elmer LS 50B spectrometer at an emission wavelength of $420 \mathrm{~nm}$ with an excitation wavelength of $350 \mathrm{~nm}$ (slits width $5 \mathrm{~nm}$ ). Cellular GSH and GSSG contents were calculated using concurrently run standard curves and expressed as nmol of GSH or GSSG per milligram of cellular protein. Cellular protein content was quantified by the Bio-Rad protein assay dye, using bovine serum albumin as the standard.

\subsection{Statistical analysis}

All data were expressed as mean \pm S.E.M. of at least three independent assays, each one in duplicate. Differ- 
ences between groups were analysed by one-way analysis of variance (ANOVA) or Student's test. A value of $p$ lower than 0.05 was considered statistically significant.

\section{Results}

\subsection{Peroxynitrite-induced morphological apoptotic changes in BAEC}

Peroxynitrite-induced cell death has been described in several cell types, including BAEC [24]. However, these reports differ not only in the cell type studied but also in the peroxynitrite source and peroxynitritetreatment and subsequently in the cell death type induced-apoptosis versus necrosis. To understand the nature of the cell death triggered by authentic peroxynitrite, BAEC toxic effects were evaluated $6 \mathrm{~h}$ after treatment of cells with peroxynitrite concentrations ranging from 100 to $600 \mu \mathrm{M}$. The plasma membrane integrity, a feature of necrosis, was assessed by measuring LDH release to the medium. A slight increase in LDH release was observed with increasing concentrations of peroxynitrite (Fig. 1A). However, this increase was not statistically different even for the highest peroxynitrite concentration tested. On the other hand, a concentrationdependent increase in apoptotic cell number, quantified after nuclear staining with Hoechst 33258, could be observed (Fig. 1B). In fact, cells treated with the highest peroxynitrite concentrations used (500 and $600 \mu \mathrm{M})$ exhibited significant nuclear condensation or fragmentation (about 20 and 30\%, respectively), whereas these apoptosis hallmarks were not evident in untreated cells (less than $2 \%$ of untreated cells exhibited nuclear condensation or fragmentation).

\subsection{Resveratrol prevented peroxynitrite-mediated apoptotic changes}

In order to determine the preventive effects of resveratrol against peroxynitrite-mediated cell death, BAEC were pre-incubated with several concentrations of resveratrol $(1-50 \mu \mathrm{M})$ for $14 \mathrm{~h}$, followed by treatment with $500 \mu \mathrm{M} \mathrm{ONOO}^{-}$as described in Section 2. Resveratrol was not present in the medium during or after peroxynitrite-treatment. Although the oxidative stress induced by $500 \mu \mathrm{M} \mathrm{ONOO}^{-}$caused apoptotic cell death of about $25 \%$ of BAEC after $6 \mathrm{~h}$ of treatment with peroxynitrite, pre-treating cells with resveratrol for $14 \mathrm{~h}$ markedly reverted the programmed cell death in a dose-dependent manner (Fig. 2). Ten micromolar of resveratrol inhibited apoptosis by $50 \%$, whereas $1 \mu \mathrm{M}$ resveratrol had no significant effect. Nearly complete protection was observed in cells pre-incubated with 25 and $50 \mu \mathrm{M}$ resveratrol.
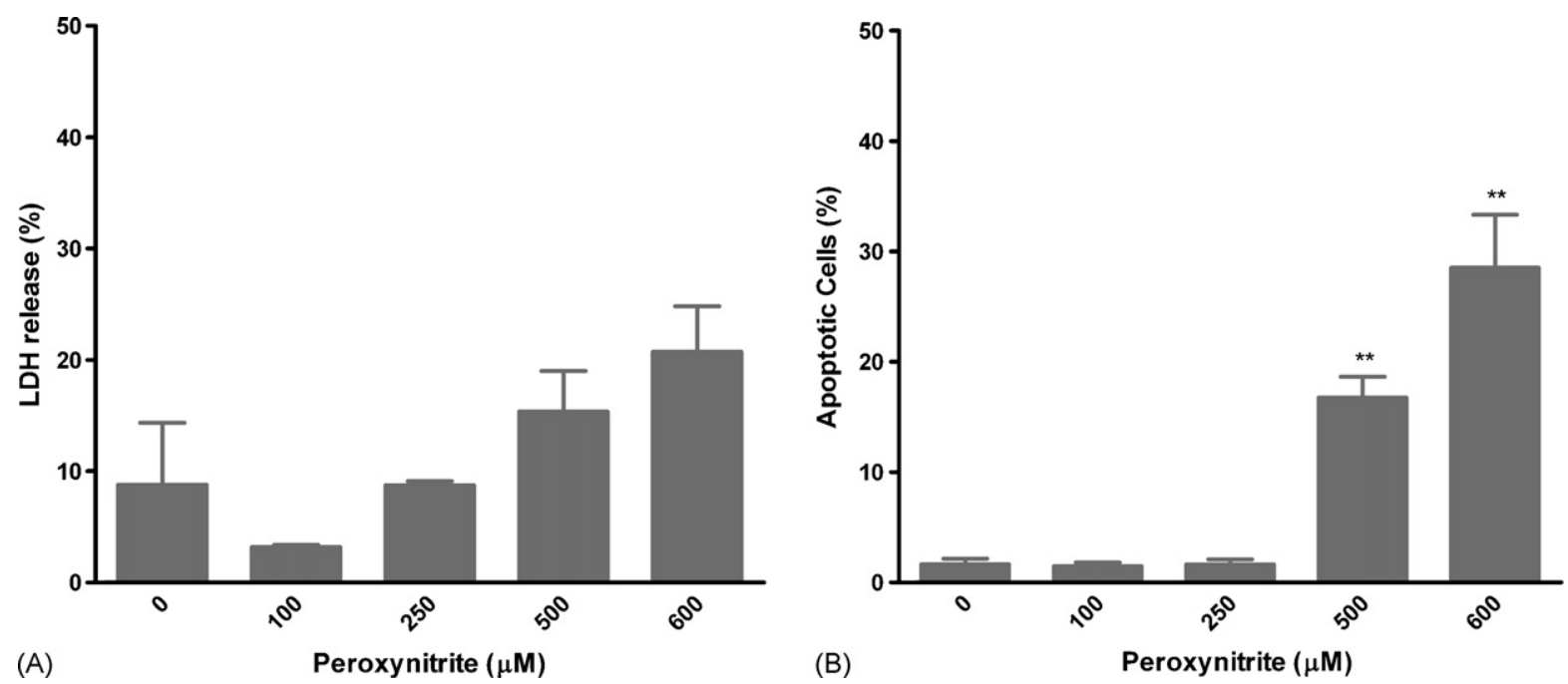

Fig. 1. Peroxynitrite induces morphological apoptotic changes in BAEC. Confluent bovine aortic endothelial cells, maintained in a medium free of serum, were treated with several concentrations of authentic peroxynitrite $(0-600 \mu \mathrm{M})$. After washing of cells with PBS, treatments were performed in $1 \mathrm{ml} /$ well of PBS for $10 \mathrm{~min}$. Subsequently, PBS was removed and replaced by fresh serum-free media and incubated at $37^{\circ} \mathrm{C}$ for $6 \mathrm{~h}$. LDH leakage (A) was evaluated in culture medium, as described in Section 2. Results were expressed as the percentage of total cell lysis. Morphological apoptotic changes (B) were assessed by nuclear morphology observation under a fluorescent microscope after nuclei staining with Hoechst 33258 , being considered apoptotic cells all those with condensed or fragmented nuclei. Results were expressed as the \% of the total cell population. Values are mean \pm S.E.M. of four experiments, each one assayed in duplicate. ${ }^{* *} p<0.01 \mathrm{vs}$. control. 


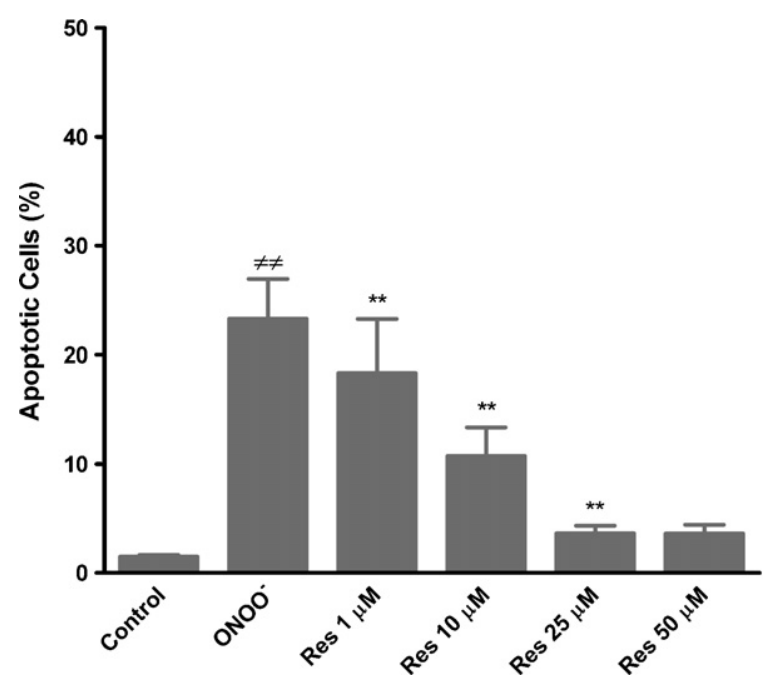

Fig. 2. Resveratrol prevents peroxynitrite-mediated apoptotic changes. Confluent bovine aortic endothelial cells maintained in a medium free of serum were pre-incubated with several concentrations of resveratrol (Res) $(1-50 \mu \mathrm{M})$ for $14 \mathrm{~h}$. Subsequently, cells were washed with PBS and treated with $500 \mu \mathrm{M}$ peroxynitrite as described in legend of Fig. 1. Morphological apoptotic changes were then assessed after nuclei staining with Hoechst 33258. Control refers to the experiment in similar conditions without peroxynitrite and resveratrol. Values are mean \pm S.E.M. of four experiments, each one assayed in duplicate. ${ }^{\neq \neq} p<0.01$ vs. control; ${ }^{* *} p<0.01$ vs. peroxynitrite-treated cells.

\subsection{Resveratrol prevented GSH depletion induced by peroxynitrite}

To evaluate the mechanism of resveratrol protection on peroxynitrite-induced apoptosis of BAEC, we examined its influence on glutathione, the most abundant cellular antioxidant and a preferential target for peroxynitrite-mediated oxidation. In agreement with this statement, a significant decrease in intracellular GSH content was detected at the end of peroxynitritetreatment (time 0). However, after this initial decrease, the cellular GSH content reached the control levels $15 \mathrm{~min}$ after the cell treatment with peroxynitrite, which were maintained for at least $180 \mathrm{~min}$. In contrast, the intracellular GSSG content increased slightly at the end of peroxynitrite-treatment, but after $15 \mathrm{~min}$ it decreased to the control level and it was maintained during all the time of the experience, as shown in Fig. 3A. Preincubation of BAEC with $50 \mu \mathrm{M}$ resveratrol prevented GSH depletion mediated by peroxynitrite in about $50 \%$, but no significant effect could be observed with $10 \mu \mathrm{M}$ resveratrol (Fig. 3B). To clarify how resveratrol prevented peroxynitrite-mediated GSH depletion as well as the differences between resveratrol concentrations tested, we analyzed the resveratrol impact, per se, on intracellular GSH and GSSG contents in the absence of peroxynitrite. As evidenced in Fig. 4, a slight increase in the constitutive intracellular GSH content was observed in cells treated with $10 \mu \mathrm{M}$ resveratrol. However, preincubation of cells with $50 \mu \mathrm{M}$ resveratrol-induced an
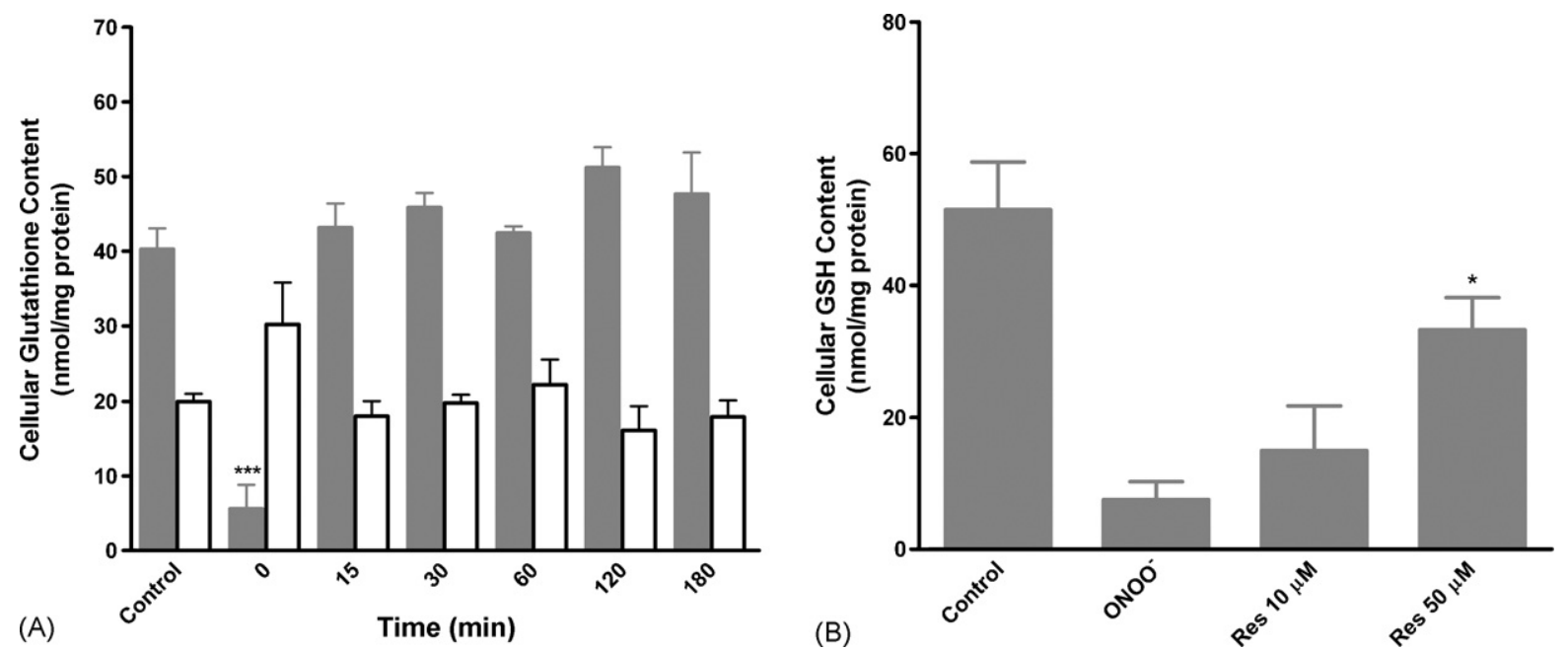

Fig. 3. Resveratrol prevents peroxynitrite-mediated glutathione depletion: (A) BAEC were incubated with $500 \mu \mathrm{M}$ peroxynitrite and GSH (grey bars) and GSSG (white bars) were quantified at different times (0-180 min) after cells treatment. (B) Cells were treated with $500 \mu \mathrm{M}$ peroxynitrite, after pre-incubation with 10 and $50 \mu \mathrm{M}$ resveratrol and GSH was quantified immediately at the end of the treatment (time 0 min) as described in Section 2. Control refers to incubated BAEC alone. Values are mean \pm S.E.M. of five experiments each one assayed in duplicate. ${ }^{* * *} p<0.001$ vs. control, ${ }^{*} p<0.05$ vs. peroxynitrite-treated cell. 


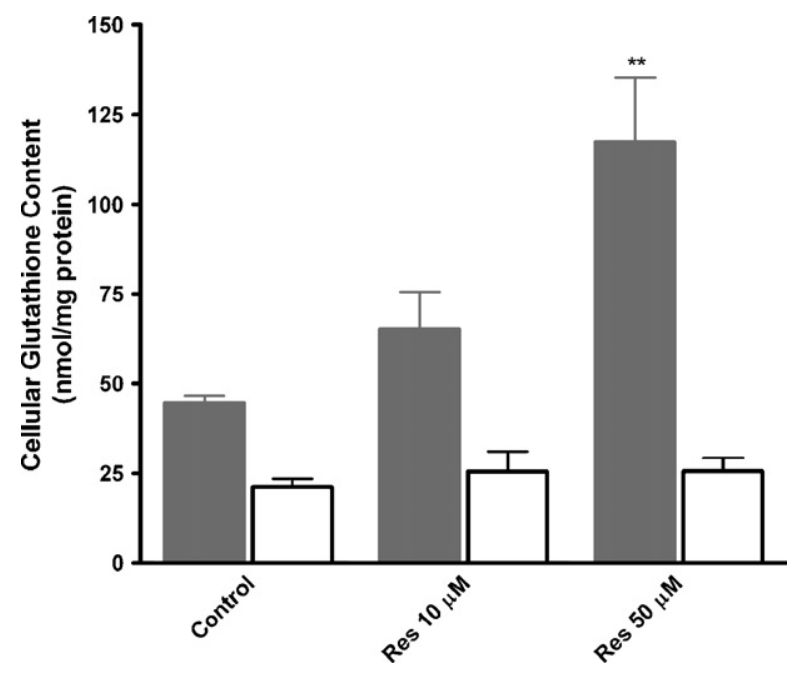

Fig. 4. Resveratrol per se increases GSH content in BAEC. Resveratrol $(10$ and $50 \mu \mathrm{M})$ was added to cells and incubated for $14 \mathrm{~h}$. Subsequently, GSH (grey bars) and GSSG (white bars) were quantified as described in Section 2. Values are mean \pm S.E.M. of six experiments each one assayed in duplicate. ${ }^{* *} p<0.01$ vs. control (experiment without resveratrol).

increase in GSH content of about two-fold. Of notice, the GSSG content was constant, either in the absence (control) or presence of resveratrol.

\subsection{BSO enhanced peroxynitrite-induced cell death}

To establish a link between the intracellular GSH content increase and the cytoprotective effect of $50 \mu \mathrm{M}$ resveratrol, cells were treated with BSO. BSO is a potent and selective inhibitor of $\gamma$-glutamylcysteinyl ligase, the rate limiting enzyme in de novo synthesis of GSH [25]. Thus, cells were firstly incubated with several concentrations of BSO for $14 \mathrm{~h}$ and the effect on the intracellular GSH content was evaluated. Whereas concentrations of 50,100 and $200 \mu \mathrm{M}$ of BSO did not significantly affect the intracellular GSH content, $500 \mu \mathrm{M}$ BSO caused a decrease in about $45 \%$ and no further decrease was observed for higher concentrations, as shown in Fig. 5A. Moreover, none of the concentrations tested affected cell viability (Fig. 5B), as evaluated by the MTT test. Accordingly, $500 \mu \mathrm{MBSO}$ was selected for further experiments. Then, the effect of BSO-induced cellular GSH depletion on cell death mediated by peroxynitrite was studied (Fig. 6). A pre-incubation of BAEC with $500 \mu \mathrm{M}$ BSO for $14 \mathrm{~h}$ followed by a treatment with several concentrations of peroxynitrite $(50-500 \mu \mathrm{M})$ resulted in a two- to three-fold increase in the apoptotic cell number, denoting a dramatic exacerbation of cytotoxicity induced by peroxynitrite. As the number of apoptotic cells observed for $250 \mu \mathrm{M} \mathrm{ONOO}^{-}$plus BSO was similar to that observed for $500 \mu \mathrm{M}$ peroxynitrite alone (Figs. 1B and 2), we used $250 \mu \mathrm{M}$ peroxynitrite to look up to the protective effects of resveratrol on peroxynitrite-induced cell death in the presence of BSO.

\subsection{Co-treatment with BSO blocked resveratrol-mediated cytoprotection}

To clarify the mechanism underlying the protection afforded by resveratrol against peroxynitrite toxicity, cells were pre-incubated with resveratrol in the presence of BSO followed by peroxynitrite-treatment. Co-
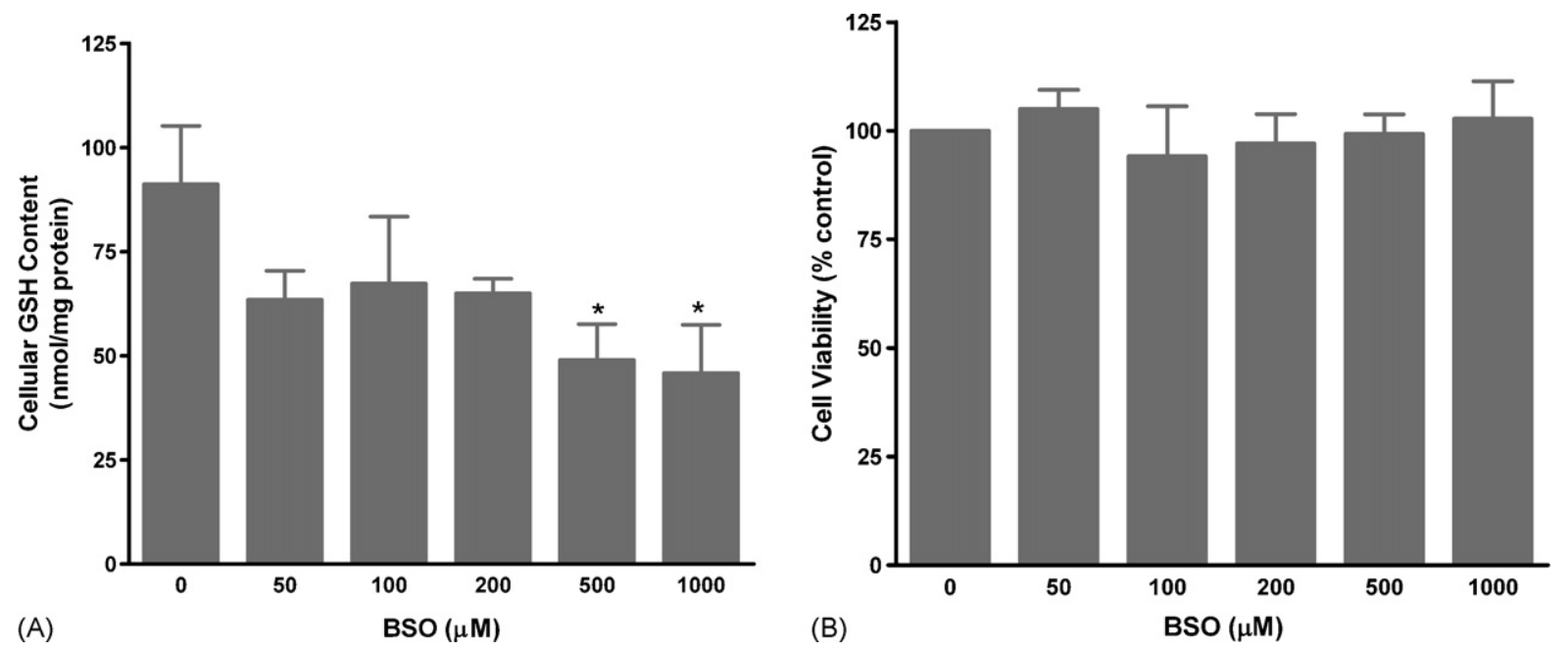

Fig. 5. BSO effects on cellular GSH content and cell viability. Cells were incubated with various concentrations of BSO (0-1000 $\mu \mathrm{M})$ for $14 \mathrm{~h}$. Then, GSH levels (A) or cell viability (B) were determined as described in Section 2. Values are mean \pm S.E.M. of three experiments each one assayed in duplicate. ${ }^{*} p<0.05$ vs. control. 


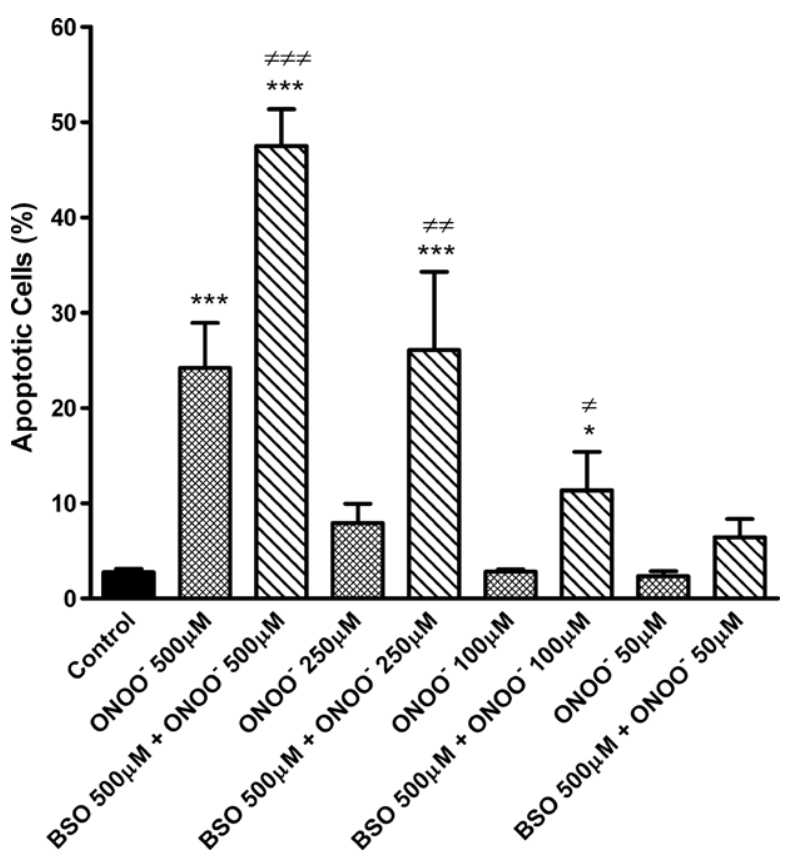

Fig. 6. BSO enhances peroxynitrite-mediated cell death. Cells preincubated in the absence or presence of $500 \mu \mathrm{M}$ BSO for $14 \mathrm{~h}$ were treated with several concentrations of peroxynitrite $(50-500 \mu \mathrm{M})$ as described previously. Six hours after peroxynitrite-treatment, the apoptotic cell number was assessed as described in Section 2. Results are expressed as the $\%$ of the total cell population. Values are mean \pm S.E.M. of four experiments, each one assayed in duplicate. ${ }^{* * * *} p<0.001$ vs. control (experiment without $\mathrm{ONOO}^{-}$and $\mathrm{BSO}$ ), ${ }^{*} p<0.05$ vs. control, $\not \neq \neq p<0.001$ vs. the same concentration of $\mathrm{ONOO}^{-}$and ${ }^{\neq \neq} p<0.01$ vs. the same concentration of $\mathrm{ONOO}^{-}$, ${ }^{\neq} p<0.05$ vs. the same concentration of $\mathrm{ONOO}^{-}$.

incubation of cells with resveratrol and BSO completely abolished the resveratrol-induced increase in cellular GSH content (Fig. 7). On the other hand, approximately $25 \%$ of cells underwent apoptosis by pre-incubation with BSO followed by $250 \mu \mathrm{M}$ peroxynitrite-treatment (Fig. 8). The co-incubation of $50 \mu \mathrm{M}$ resveratrol with BSO slightly protected cells against apoptosis mediated by $\mathrm{ONOO}^{-}$, as the number of apoptotic cells decreased only about $6 \%$ relative to the control, i. e., the assay without resveratrol (Fig. 8). Therefore the protection afforded by resveratrol in endothelial cells against $\mathrm{ONOO}^{-}$was significantly reduced in the presence of BSO when compared with that observed in similar conditions without BSO (a decrease in about $21 \%$ relative to the assay with $\mathrm{ONOO}^{-}$alone) (Fig. 2).

\section{Discussion}

A large body of evidences point to a prominent role of resveratrol as an anti-atherosclerotic agent [see 26 for review and references in there]. This has been, par-

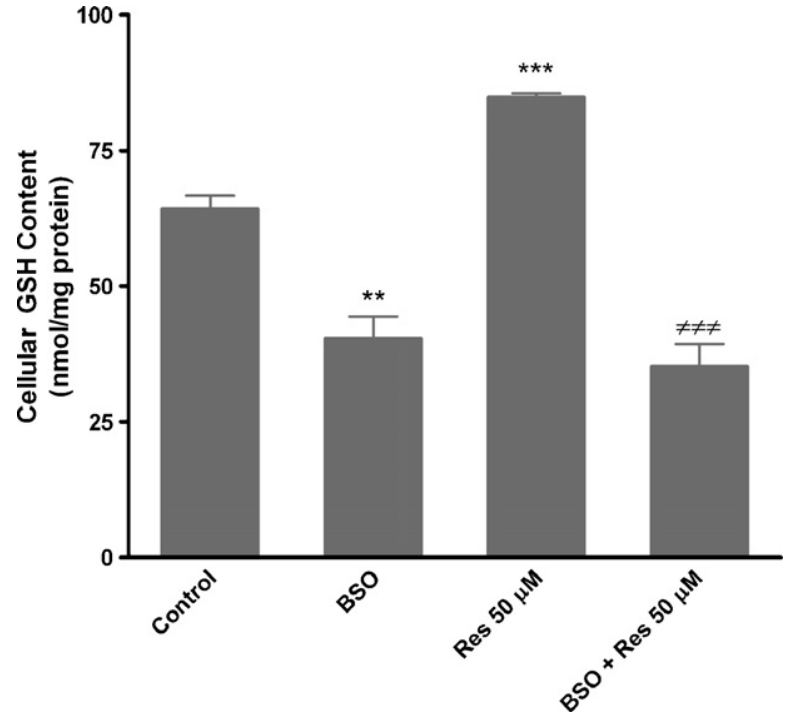

Fig. 7. BSO reverts the resveratrol-induced increase in cellular GSH content. Cells were incubated with either $500 \mu \mathrm{M}$ BSO, or $50 \mu \mathrm{M}$ resveratrol or both, for $14 \mathrm{~h}$. GSH cellular levels were then quantified as described in Section 2. Values are mean \pm S.E.M. of three experiments, each one assayed in duplicate. ${ }^{* *} p<0.01$ vs. control (experiment without BSO and Res), ${ }^{* * *} p<0.001$ vs. control and ${ }^{\neq \neq \neq} p<0.001$ vs. resveratrol.

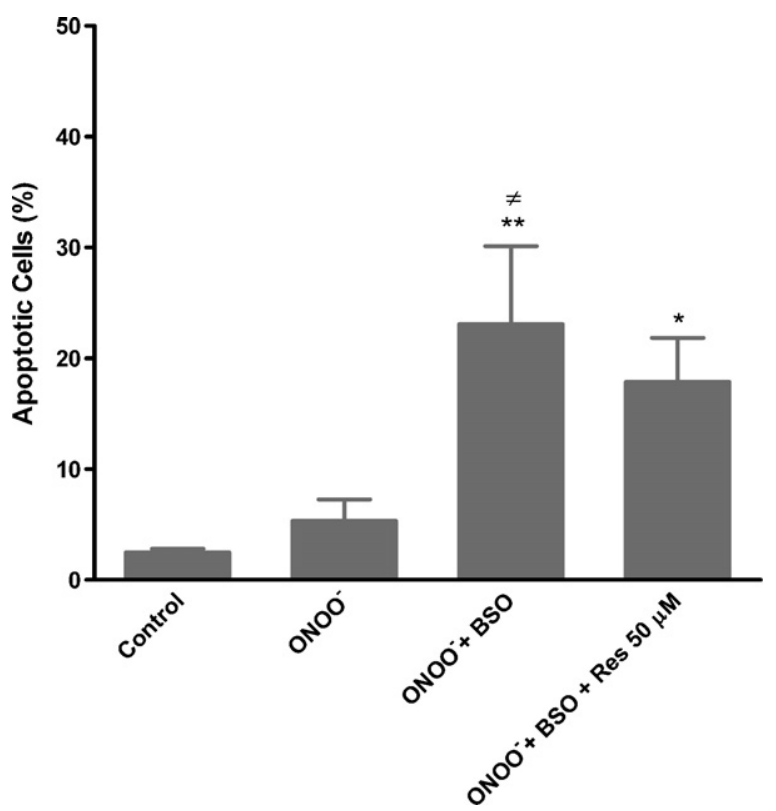

Fig. 8. BSO inhibits resveratrol protective effects in peroxynitritemediated cell death. BAEC alone (control) or pre-treated with $500 \mu \mathrm{M}$ BSO or $500 \mu \mathrm{M}$ BSO plus $50 \mu \mathrm{M}$ resveratrol, were incubated with $250 \mu \mathrm{M}$ peroxynitrite for $10 \mathrm{~min}$ in PBS. The number of apoptotic cells was assessed $6 \mathrm{~h}$ after this treatment. Results are expressed as the percentage of the total cell population. Values are mean \pm S.E.M. of five experiments, each one assayed in duplicate. ${ }^{* *} p<0.01 \mathrm{vs.} \mathrm{control,}$ ${ }^{*} p<0.05$ vs. control and ${ }^{\neq} p<0.05$ vs. $\mathrm{ONOO}^{-}$. 
tially, supported by its ability to reduce oxidative stress occurring in the arterial wall during the atherosclerotic process. Resveratrol has been shown to reduce LDL oxidation, a significant contributor to oxidative stress in the vasculature and a critical event in atherogenesis, mediated by different initiators, such as copper, peroxynitrite and ferrylmyoglobin $[14,15]$. Furthermore, resveratrol can affect several enzymatic systems leading to a decrease in the formation of intracellular oxidant reactive species in vascular cells, as well as, to an improvement in the cellular redox state, via antioxidants induction, increasing cell resistance to injury elicited by reactive species [26 and references therein]. Actually, in vitro studies, carried out by $\mathrm{Cao}$ and $\mathrm{Li}$ [18] in cardiomyocytes and by $\mathrm{Li}$ et al. [19] in aortic smooth muscle cells, demonstrate that resveratrol induces an increase in either cellular GSH content, or in different enzyme activities, namely glutathione-dependent enzymes, catalase and superoxide dismutase. In addition, preliminary in vivo studies from the same authors point out that resveratrol is also capable of inducing the expression of cardiac antioxidants and phase two enzymes in mice after oral administration [27]. On the other hand, it is well known that glutathione and related enzymes are important cellular tools to detoxify oxidants, namely peroxynitrite. Actually, several recent studies report that GSH depletion enhances peroxynitrite-induced stress, characterized for example by an inflammatory response and vascular injury [28]. Previously, we have reported that resveratrol prevents efficiently the LDL apoprotein from oxidation mediated by peroxynitrite, being resveratrol rather oxidized than nitrated by such species [15]. Taking into account all this background, we investigated whether resveratrol could protect cells from peroxynitrite-mediated injury and looked up to a possible underlying mechanism via intracellular GSH, as to our knowledge no report exists in this issue.

Our results show that addition of authentic peroxynitrite to BAEC elicited a non-necrotic programmed cell death, at the highest concentrations tested (500 and $600 \mu \mathrm{M})$, triggering condensation and fragmentation of nucleus without LDH leakage to the medium (Fig. 1A and B). Such effects are in agreement with those reported by Foresti et al. [24], suggesting an apoptotic pathway for peroxynitrite-induced cell death. However, results from Szabó et al. [29], with a similar range of peroxynitrite concentrations, are controversial suggesting a different pattern of cell death since they observed activation of the nuclear enzyme poly-ADP-ribose polymerase, an event related to cell necrosis rather than apoptosis [30]. These different effects may be the result of different experimental conditions, such as the exposure time of the cells to the oxidant and the medium used, cell culture medium or buffer. As referred above, and on basis of preliminary work (results not shown), phosphate buffer was used to avoid the secondary effects of the reaction products between peroxynitrite and DMEM.

Pre-incubation of cells with 10,25 and $50 \mu \mathrm{M}$ resveratrol, for $14 \mathrm{~h}$, significantly protected them from peroxynitrite-mediated injury (Fig. 2), an effect not observed at the lowest concentration tested $(1 \mu \mathrm{M})$. Nevertheless, only at the highest concentration $(50 \mu \mathrm{M})$ resveratrol prevented significantly the GSH depletion induced by peroxynitrite (Fig. 3B) which is in agreement with the observation that only at this concentration a significant increase in the intracellular GSH pool was stimulated by resveratrol per se (Fig. 4). It should be highlighted that resveratrol effects can be ascribed to its direct action on cell, since it was removed from the medium before the oxidant cell treatment. On the other hand, the decrease in GSH after peroxynitrite-treatment was not followed by the corresponding increase in oxidized glutathione (GSSG), as shown in Fig. 3A, suggesting that this decrease was rather due to a removal of GSH out of the cell or to a $S$-nitrosation of glutathione by peroxynitrite [11,31].

As aforementioned, GSH is a key player in peroxynitrite-detoxification, either directly as a scavenger or indirectly as a cofactor of the enzymes serving the glutathione-mediated detoxification process. To provide a direct evidence for the involvement of resveratrolinduced GSH increase in its cytoprotective effect against peroxynitrite, a series of experiments were designed in the presence of an inhibitor of GSH synthesis, such as BSO. BSO inhibits specifically and irreversibly the $\gamma$ glutamylcysteine synthetase ( $\gamma$-GCS), thereby limiting the intracellular GSH $[11,25]$. Actually, de novo synthesis of GSH is mediated by two ATP-dependent enzymes: the $\gamma$-GCS and the glutathione synthetase, being the former the rate limiting enzyme, subject to a feedback inhibition by GSH. Another relevant factor in de novo GSH synthesis is the availability of cysteine [25]. This could explain the rapid recovery ( $15 \mathrm{~min}$ ) of intracellular GSH content after peroxynitrite-treatment (Fig. 3A) given that at this time, the cells had been already in the presence of cell culture medium containing available cysteine for cellular uptake and subsequently for GSH synthesis. The co-incubation of cells with peroxynitrite and a non-toxic concentration of BSO enhanced significantly cell death caused by peroxynitrite (Fig. 6), supporting the important role of GSH in the protection against oxidant species. Moreover, BSO was able to abolish the intracellular GSH increase due to the pre-incubation of cells with $50 \mu \mathrm{M}$ resveratrol (Fig. 7), pointing out that resveratrol- 
mediated GSH increase occurred through induction of $\gamma$-GCS.

To clarify the resveratrol cytoprotective strategy against peroxynitrite-mediated cell death we compared such protection in the absence and presence of BSO (Fig. 8). Of note, on basis of the results from Fig. 6, in the experiment with BSO we used only $250 \mu \mathrm{M}$ peroxynitrite. Interestingly, cells pre-incubated for $14 \mathrm{~h}$ with $50 \mu \mathrm{M}$ resveratrol were strongly protected against injury elicited by peroxynitrite alone (Fig. 2), but in the presence of BSO, no significant protection could be observed (Fig. 8). These results strongly suggest that resveratrol, at a concentration of $50 \mu \mathrm{M}$ prevents cells from peroxynitrite deleterious effects by increasing the intracellular GSH pool.

Regarding the molecular mechanisms by which an increase in intracellular GSH protects cells from death induced by peroxynitrite several pathways are possible. On the one hand, the two-fold increase in GSH induced by resveratrol, shown in this work, could slightly increase the cellular capacity to reduce peroxynitrite through a non-catalyzed reaction. On the other hand, the increase in cellular GSH concentration increases the glutathione peroxidase activity (GPx), a biologically efficient peroxynitrite-detoxification pathway in vivo. In fact, kinetic studies show that the GPx-catalyzed reaction of peroxynitrite outcompetes the non-catalyzed reduction of peroxynitrite with GSH by a factor of $3[32,33]$. Also, glutathione $S$-transferases could be implicated in the resveratrol protective mechanism. Some of these enzymes, namely the microsomal ones, exhibit a glutathione peroxidase activity, reducing lipid hydroperoxides generated in cellular membranes by oxidants. Thus, the increase in the cellular levels of GSH, may increase the peroxidase activity of GST decreasing lipid peroxidation products and consequently modulating signalling for apoptosis. Worthy of note, the microsomal GST is activated by peroxynitrite [34,35].

At lower concentrations, a different protective pathway must be implicated. Actually, $10 \mu \mathrm{M}$ resveratrol reduced efficiently peroxynitrite-induced cell death (Fig. 2) but such protection was not associated neither with a significant inhibition of GSH depletion in the presence of the oxidant (Fig. 3B) nor with a significant increase in the GSH intracellular content (Fig. 4). Therefore, resveratrol, at this concentration and in our model system, has a protective role in the biochemical pathways implicated in the peroxynitrite-induced cell death, but a large number of potential mechanisms may be considered as peroxynitrite may mediate cell injury and cell death by multiple pathways [36].
In conclusion, our study demonstrates for the first time that a long pre-incubation of BAEC with resveratrol is able to rescue endothelial cells from injury triggered by authentic peroxynitrite in a concentration-dependent manner. Furthermore, this cytoprotective effect seems to be afforded by an increase in the intracellular GSH pool for the highest concentration of resveratrol tested. Thus, our data provides a strong contribution to the view that resveratrol cardioprotective effects go far beyond its classical antioxidant activity, being able to modulate redox cellular state by increasing the GSH intracellular levels.

\section{Acknowledgments}

This work was supported by POCTI grants (35019/AGR/2000 and AGR/599919/2004). Paula Brito is a recipient of the fellowship SFRH/BD/7986/2001.

\section{References}

[1] A.J. Lusis, Atherosclerosis, Nature 407 (2000) 233-241.

[2] H. Cai, D.G. Harrison, Endothelial dysfunction in cardiovascular diseases. The role of oxidant stress, Circ. Res. 87 (2000) 840-844.

[3] W.H. Koppenol, The basic chemistry of nitrogen monoxide and peroxynitrite, Free Radic. Biol. Med. 25 (1998) 385-391.

[4] M.G. Salgo, K. Stone, G.L. Squadrito, J.R. Battista, W.A. Pryor, Peroxynitrite causes DNA nicks in plasmid pBR322, Biochem. Biophys. Res. Commun. 210 (1995) 1025-1030.

[5] H. Ischiropoulos, A.B. al-Mehdim, Peroxynitrite-mediated oxidative protein modifications, FEBS Lett. 364 (1995) 279-282.

[6] R. Radi, J.S. Beckman, K.M. Bush, B.A. Freeman, Peroxynitriteinduced membrane lipid peroxidation: the cytotoxic potential of superoxide and nitric oxide, Arch. Biochem. Biophys. 288 (1991) 481-487.

[7] V.M. Darley-Usmar, N. Hogg, V.J. O'Leary, M.T. Wilson, S. Moncada, The simultaneous generation of superoxide and nitric oxide can initiate lipid peroxidation in human low density lipoprotein, Free Radic. Res. Commun. 17 (1992) 9-20.

[8] C. Leeuwenburgh, M.M. Hardy, S.L. Hazen, P. Wagner, S. Ohishi, U.P. Steinbrecher, J.W. Heinecke, Reactive nitrogen intermediates promote low density lipoprotein oxidation in human atherosclerotic intima, J. Biol. Chem. 272 (1997) 1433-1436.

[9] H. Rubbo, V. O'Donnell, Nitric oxide, peroxynitrite and lipoxygenase in atherogenesis: mechanistic insights, Toxicology 208 (2005) 305-317.

[10] J.S. Beckmann, Y.Z. Ye, P.G. Anderson, J. Chen, M.A. Accavitti, M.M. Tarpey, C.R. White, Extensive nitration of protein tyrosines in human atherosclerosis detected by immunohistochemistry, Biol. Chem. Hoppe-Seyler 375 (1994) 81-88.

[11] A. Pastore, G. Federici, E. Bertini, F. Piemonte, Analysis of glutathione: implication in redox and detoxification, Clin. Chim. Acta 333 (2003) 19-39.

[12] L.O. Klotz, H. Sies, Defenses against peroxynitrite: selenocompounds and flavonoids, Toxicol. Lett. 140/141 (2003) 125-132.

[13] X.L. Ma, B.L. Lopez, G.L. Liu, T.A. Christopher, F. Gao, Y. Guo, G.Z. Feuerstein, R.R. Ruffolo Jr., F.C. Barone, T.L. Yue, Hypercholesterolemia impairs a detoxification mechanism against per- 
oxynitrite and renders the vascular tissue more susceptible to oxidative injury, Circ. Res. 80 (1997) 894-901.

[14] E.N. Frankel, A.L. Waterhouse, J.E. Kinsella, Inhibition of human LDL oxidation by resveratrol, Lancet 341 (1993) 1103-1104.

[15] P. Brito, L.M. Almeida, T.C.P. Dinis, The interaction of resveratrol with ferrylmyoglobin and peroxynitrite; protection against LDL oxidation, Free Radic. Res. 36 (2002) 621-631.

[16] Y. Liu, G. Liu, Isorhapontigenin and resveratrol suppress oxLDLinduced proliferation and activation of ERK1/2 mitogen-activated protein kinases of bovine aortic smooth muscle cells, Biochem. Pharmacol. 67 (2004) 777-785.

[17] C.R. Pace-Asciak, S. Hahn, E.P. Diamandis, G. Soleas, D.M. Goldberg, The red wine phenolics trans-resveratrol and quercetin block human platelet aggregation and eicosanoid synthesis: implications for protection against coronary heart disease, Clin. Chim. Acta 235 (1995) 207-219.

[18] Z. Cao, Y. Li, Potent induction of cellular antioxidants and phase 2 enzymes by resveratrol in cardiomyocytes: protection against oxidative and electrophilic injury, Eur. J. Pharmacol. 489 (2004) $39-48$.

[19] Y. Li, Z. Cao, H. Zhu, Upregulation of endogenous antioxidants and phase 2 enzymes by the red wine polyphenol, resveratrol in cultured aortic smooth muscle cells leads to cytoprotection against oxidative and electrophilic stress, Pharmacol. Res. 53 (2006) 6-15.

[20] T.C.P. Dinis, C.L. Santos, L.M. Almeida, The apoprotein is the preferential target for peroxynitrite-induced LDL damage protection by dietary phenolic acids, Free Radic. Res. 36 (2002) 531-543.

[21] R.M. Uppu, G.L. Squadrito, R. Cueto, W.A. Pryor, Selecting the most appropriate synthesis of peroxynitrite, Method Enzymol. 269 (1996) 285-295.

[22] F. Denizot, R. Lang, Rapid colorimetric assay for cell growth and survival. Modifications to the tetrazolium dye procedure giving improved sensitivity and reliability, J. Immunol. Method 89 (1986) 271-277.

[23] P.J. Hissin, R. Hilf, A fluorimetric method for determination of oxidized and reduced glutathione in tissues, Anal. Biochem. 74 (1976) 214-226.

[24] R. Foresti, P. Sarathchandra, J.E. Clark, C.J. Green, R. Motterlini, Peroxynitrite induces haem oxygenase-1 in vascular endothe- lial cells: a link to apoptosis, Biochem. J. 339 (1999) 729736.

[25] M.E. Anderson, Glutathione: an overview of biosynthesis and modulation, Chem. Biol. Interact. 111/112 (1998) 1-14.

[26] D. Delmas, B. Jannin, N. Latruffe, Resveratrol: preventing properties against vascular alterations and ageing, Mol. Nutr. Food Res. 49 (2005) 377-395.

[27] Y. Li, Z. Cao, Chemical induction of endogenous antioxidants in mouse cardiac tissue: implications for cardioprotection, Toxicol. Sci. 78 (Suppl. 1) (2004) 168.

[28] S. Cuzzocrea, B. Zingarelli, M. O'Connor, A.L. Salzman, C. Szabo, Effect of L-buthionine-(S,R)-sulphoximine, an inhibitor of gamma-glutamylcysteine synthetase on peroxynitrite- and endotoxic shock-induced vascular failure, Br. J. Pharmacol. 123 (1998) 525-537.

[29] C. Szabó, S. Cuzzocrea, B. Zingarelli, M. O’Connor, A.L. Salzman, Endothelial dysfunction in a rat model of endotoxic shock. Importance of the activation of poly (ADP-ribose) synthetase by peroxynitrite, J. Clin. Invest. 100 (1997) 723-735.

[30] C. Szabó, Poly(ADP-ribose) polymerase activation by reactive nitrogen species-relevance for the pathogenesis of inflammation, Nitric oxide 14 (2006) 169-179.

[31] A. Schrammel, A.C.F. Gorren, K. Schmidt, S. Pfeiffer, B. Mayer, S-nitrosation of glutathione by nitric oxide, peroxynitrite, and $\mathrm{NO}^{\bullet} / \mathrm{O}_{2}{ }^{\bullet}$, Free Radic. Biol. Med. 34 (2003) 1078-1088.

[32] K. Briviba, R. Kissner, W.H. Koppenol, H. Sies, Kinetic studies of the reaction of glutathione peroxidase with peroxynitrite, Chem. Res. Toxicol. 11 (1998) 1398-1401.

[33] H. Sies, G.E. Arteel, Interaction of peroxynitrite with selenoproteins and glutathione peroxidase mimics, Free Radic. Biol. Med. 28 (2000) 1451-1455.

[34] Y. Yang, J.Z. Cheng, S.S. Singhal, M. Saini, U. Pandya, S. Awasthi, Role of glutathione $S$-transferases in protection against lipid peroxidation. Overexpression of hGSTA2-2 in K562 cells protects against hydrogen peroxide-induced apoptosis and inhibits JNK and caspase 3 activation, J. Biol. Chem. 276 (2001) 19220-19230.

[35] Y. Bin, B.M. Bennet, Activation of microssomal glutathione $S$ transferase by peroxynitrite, Mol. Pharmacol. 63 (2003) 136-146.

[36] C. Szabó, Multiple pathways of peroxynitrite cytotoxicity, Toxicol. Lett. 140/141 (2003) 105-112. 